\title{
DISPOSITIVOS DE TRANSFORMAÇÃO DO SOFRIMENTO EM ADOECIMENTO NUMA EMPRESA
}

\author{
Luiz Carlos Brant \\ Carlos Minayo-Gómez
}

\begin{abstract}
RESUMO. O dispositivo como mecanismo institucional alcança nova ordem e disposição para atingir um fim. Identificamos instrumentos transformadores do sofrimento em adoecimento. Entrevistamos trabalhadores, gestores e profissionais da saúde do setor de serviços, em Belo Horizonte. O mascaramento do sofrimento, a sustentação e regulação da morbidade e a construção da identidade de doente constituíram alguns dispositivos. Esses mecanismos articulavam-se com o desenvolvimento das neurociências. O sentido clássico da cura é substituído pela psiquiatrização, através de uma interpretação individualizante e medicalização abusiva. Concluiu-se que esses instrumentos inseriam-se na transição das "sociedades disciplinares" para as "de controle". Os dispositivos utilizados na gestão do trabalho, embora permitissem avanços profissionais, agudizavam o controle sobre o corpo, o domínio dos espaços da vida privada e a culpabilização dos trabalhadores pelo processo saúde-doença-cuidado, favorecendo a transformação do sofrimento em adoecimento.
\end{abstract}

Palavras-chave: sofrimento psíquico, saúde do trabalhador, Psicologia.

\section{TRANSFORMATION DEVICES FROM SUFFERING TO ILLNESS WITHIN A SERVICE FIRM}

\begin{abstract}
The conception of device as an institutional mechanism reaches a new landing and attitude so that a specific purpose may be attained. Mechanisms that transform suffering into illness are identified. Workers, health professionals and managers in the service sector in Belo Horizonte, Brazil, have been interviewed. The disguise of suffering, the maintenance and regulation of morbidity, and the construction of an identity as a diseased person constitute a set of devices. These mechanisms were articulated within the development of Neuroscience. The classical meaning of cure has been substituted by the "psychiatrization" through an individualizing interpretation and over-medicalization. These mechanisms have been inserted with the transition movement from 'disciplinary societies' to 'control societies'. They even promoted firm control over the body, predominance in private life spaces and workers' culpability for the health-illness-care process. Consequently, the transformation of suffering into illness is enhanced.
\end{abstract}

Key words: Suffering, worker's health, Psychology.

\section{DISPOSITIVOS DE TRANSFORMACIÓN DEL SUFRIMIENTO EN PADECIMIENTO EM UNA EMPRESA}

\begin{abstract}
RESUMEN. A partir del entendimiento del dispositivo como mecanismo institucional para alcanzar un fin, identificamos varios instrumentos transformadores del sufrimiento en padecimiento. Entrevistamos trabajadores, gestores e profesionales de salud de una empresa del sector de servicios de Belo Horizonte. El enmascaramiento del sufrimiento, la sustentación y regulación de la morbilidad y la construcción de la identidad de enfermo constituyeron algunos de los dispositivos, que están en consonancia con el desarrollo de las neurociencias. El sentido clásico da curación es substituido por la psiquiatrización, a través de una interpretación individualizante y de medicalización abusiva. Concluyese que esos instrumentos hacen parte de la transición de las "sociedades disciplinares" para las "de control". A pesar de que permiten avances profesionales, agudizan el control sobre el cuerpo, la dominación de espacios de la vida privada y la culpabilización de los trabajadores por el proceso salud-enfermedad-cuidado, favoreciendo la transformación del sufrimiento en padecimiento.
\end{abstract}

Palabras-clave: sufrimiento psíquico, salud del trabajador, psicología.

* Doutor em Ciências da Saúde. Escola Nacional de Saúde Pública, Fundação Oswaldo Cruz.

\# Doctor en Ciencias. Centro de Estudo da Saúde do Trabalhador e Ecologia Humana, Fundação Oswaldo Cruz. 
A idéia de sofrimento está fortemente associada a morte, doenças, conflitos interpessoais e dificuldades financeiras, ou seja, a situações de perda. Com esses diferentes sentidos, a categoria sofrimento se aproxima daquilo que Levi-Strauss (1974) denominou de "significante flutuante", e traz em seu bojo uma diversidade de significados. Para Birman (2006), a alteridade implicada no conceito de sofrimento é crucial como elemento fundamental de leitura para colocar em evidência novas formas de subjetivação. Quando relacionada ao trabalho, a idéia de sofrimento evoca, também, sentidos que vão do medo da perda do emprego ao da designação para um novo cargo, da angústia diante das tarefas simples ou daquelas de alta complexidade, compondo uma mesclagem de emoções tanto "positivas como negativas". Na era pósindustrial, a manifestação do sofrimento tornou-se um verdadeiro tabu. É vista como ausência de motivação, fraqueza de caráter ou desequilíbrio emocional. $\mathrm{O}$ processo de reestruturação organizacional exige que o sujeito se mantenha aberto, sem medo das transformações; que corra riscos com otimismo e, sobretudo, expresse satisfação com a vida. Em face desses imperativos, o sofrimento não pode ser reconhecido como tal, pois suas manifestações contrariariam a exaltação do eu diante das estratégias de estetização das empresas.

No entanto, independentemente das vontades individuais e das ordens institucionais, o sofrimento entra na cena do sujeito. Embora sem lugar na "cultura do narcisismo", quando transformado em adoecimento torna-se tolerável, pois nesse contexto o peso moral da doença é menor. Temos, portanto, como pressuposto, que as manifestações do sofrimento, em determinados espaços institucionais, passam por um processo de adoecimento; entendido como atribuição e introjeção da identidade de doente, independentemente da existência ou não de uma doença. A gestão do trabalho constituiria um desses lugares, visto que está inserida na transição das "sociedades disciplinares", segundo Foucault (1979), para as "sociedades de controle", de acordo com Deleuze (1992). O presente artigo tem como objetivo identificar e compreender os dispositivos de controle capazes - segundo a concepção foucaultiana - de contribuir para a transformação do sofrimento, uma vez manifestado no âmbito do trabalho, em adoecimento.

\section{SOFRIMENTO E ADOECIMENTO}

O sofrimento impele o sujeito ao ato pela vida. "No princípio era a ação", segundo Goethe (1832/1970, p. 80), frase que Freud (1930/1997) costumava repetir. $\mathrm{O}$ conhecimento cognitivo pouco pode ajudar o homem e não é suficiente para impedir ou eliminar o sofrimento, ao contrário, pode paralisar a sua ação, devido a um excesso de reflexão ou de possibilidades. "A visão horrível da verdade sobrepuja todo motivo que impeliria o agir (...) que requer que se esteja envolto no véu da ilusão" (Nietzsche, 1871/1978, p. 9). "Por um longo tempo, lutei sem cessar pela minha felicidade, hoje, luto pelo meu trabalho" (Nietzsche, 1871/1978, p. 96).

Em sua dimensão simbólica, o trabalho permite a manifestação e a elaboração do sofrimento e configura o semblante do necessário véu para a ação transformadora. O trabalho oferece ainda ao sujeito um lugar numa parte da árdua realidade humana e é indispensável à preservação e justificação da existência em comunidade. Embora possa se constituir também em fonte de sofrimento, não significa castigo, representação comum na tradição da moral judaicocristã, com seu ressentimento e ideal ascético. Portanto, é apenas no relacionamento com outros homens que o trabalho pode vir a se constituir como dispositivo de sofrimento ou punição.

Em estudos no campo da saúde do trabalhador, é comum o estabelecimento da articulação entre sofrimento psíquico no trabalho e a raiz latina do vocábulo tripalium - instrumento de castigo aplicado aos escravos que desobedeciam. A mesma correlação também se faz com a palavra francesa travail aparelho de contenção de animais em cirurgias -, ou com a inglesa labour, que assinala situações de penosidade e de fadiga. Na perspectiva bíblica, a condenação imposta a Adão e seus descendentes de ter que arrancar o sustento com trabalhos penosos, todos os dias da vida, segue essa mesma linha de raciocínio. Ao centrar a questão em termos de trabalho-punição, oculta-se o sofrimento nessa relação, dificultando a visualização da presença ameaçadora de um terceiro (Senhor), que está na gênese do sofrimento, uma vez que a dimensão da alteridade é condição sine qua non para suscitá-lo.

Assim, o sofrimento é uma reação às ameaças à existência humana que podem surgir - além de outras fontes: do próprio corpo, condenado à decadência e à dissolução; do mundo externo que pode voltar-se contra comunidades inteiras com forças de destruição esmagadoras e impiedosas; e, por fim, dos relacionamentos com os outros homens. $\mathrm{O}$ sofrimento originário do conjunto das relações entre os sujeitos, na perspectiva psicanalítica, é mais penoso do que qualquer outro (Freud, 1930/1997). Logo, as manifestações do sofrimento e seus destinos se 
referem às condições de intensificação ou conservação, aumento ou diminuição da vida.

Enquanto o sofrimento remete à concepção de reação e vontade de viver como fundamento da vida, o adoecimento é expressão de inércia e insurreição contra a vontade afirmativa de transformação. Denominamos como adoecimento o processo de construção da identidade de doente a partir da manifestação do sofrimento, independentemente da presença ou ausência de doença. A doença não é somente o desaparecimento de uma ordem fisiológica, mas o aparecimento de uma nova ordem vital; logo não há desordem, apenas a substituição de uma ordem esperada por outra, que de nada serve, mas que é necessário suportar. Pessoas que desconhecem ter uma doença não se sentem doentes, até que profissionais da saúde, munidos de informações clínicas e técnicas de laboratórios, dão-lhes um diagnóstico. Tornam-se, geralmente, herdeiros de uma cultura médica e, habitualmente, medicamentosa. Nietzsche, inspirandose em Claude Bernard, e, mais precisamente, na idéia de que o patológico e o normal são homogêneos, conclui que o valor de todos os estados mórbidos consiste em mostrar, como em uma lente de aumento, certas condições que, apesar de normais, dificilmente são visíveis no estado normal (Canguilhem, 2000). A identidade de doente é um valor, é histórica, social, produzida e, portanto, passível de questionamento. Nesse sentido, constitui também um valor niilista, uma vez que decorre de uma desvalorização da vida em nome de outros valores (Machado, 1999).

\section{MÉTODO}

Para atingir o objetivo proposto, buscou-se uma empresa do setor de serviços, na Região Metropolitana de Belo Horizonte. Estabelecemos interlocuções, através de entrevistas abertas com trabalhadores, gestores e profissionais da saúde, tendo como foco o sofrimento manifestado no trabalho. Foram entrevistados 13 trabalhadores, dos quais 6 estavam afastados por motivo de doença; 8 profissionais da saúde (3 médicos, 2 psicólogos, 1 dentista, 1 enfermeira e 1 assistente social); 13 gestores (1 aposentado por invalidez). Buscou-se contemplar empregados de vários setores, no período de 2001 a 2003, quando a empresa encontrava-se em reestruturação tecnológica e gerencial. Todos foram escutados como informantes privilegiados da sua história, portadores de um saber emanado da experiência. Os depoimentos, fruto do recordar, repensar e rememorar, não constituíram apenas matéria-prima forjada no plano da linguagem, mas ações de trabalhadores, gestores e profissionais da saúde fazendo uso do momento da entrevista para enfrentamento de certas contingências organizacionais, uma vez que conheciam os objetivos da pesquisa. Diante dessa constatação, tivemos que semiestruturar algumas entrevistas, estabelecendo alguns limites, de modo que o entrevistado pudesse falar tanto da sua trajetória de vida e trabalho, com foco no processo sofrimento-adoecimento-cuidado, quanto de seu posicionamento diante da reestruturação organizacional.

Do ponto de vista metodológico, trata-se de um estudo qualitativo, tendo como método de análise o hermenêutico-dialético, que busca as bases da compreensão da realidade por meio da linguagem, introduzindo o princípio do conflito e da contradição, segundo a concepção de Minayo e Deslandes (2002).

\section{RESULTADOS E DISCUSSÕES}

\section{A reestruturação organizacional}

Os trabalhadores conhecem e sentem os medos, os sustos e as arbitrariedades das relações de trabalho, mas também aprenderam a erguer resistências e a estabelecer negociações. $\mathrm{O}$ contexto da reestruturação produtiva, das últimas décadas do século XX, é marcado pelo curto prazo, segundo Sennet (2000), mediado por um processo de alta competição. A capacidade de pensar, criar e tomar decisões passou a ser mais incorporada aos processos de trabalho. No faz-e-desfaz dos projetos e setores da empresa investigada, cada trabalhador tornava-se um competidor individual, procurando traçar estratégias de sobrevivência, na tentativa de maximizar uma prática merecedora do posto ocupado, e, gradativamente, isolava-se:
"eu tive que adaptar. Teve gente que se acomodou. O pessoal está acostumado com imagem de funcionário público. Estou fazendo a minha parte, buscando oportunidade de aprender; temos cursos aqui, vou tentar voltar para faculdade. Eles ficam rindo de mim, dizendo que estou velho para isso, dizem que sou puxa-saco. Isto está me deixando irritado, alguns eu nem cumprimento mais" (JF, trabalhador do setor administrativo).

O sofrimento derivado da organização do trabalho - percurso já trilhado por tantos trabalhadores ao longo da história - não é novo, embora não tenha 
recebido a atenção devida enquanto uma reação do sujeito. Algumas de suas manifestações, na era pósindustrial, são reveladoras não apenas dessa falta de cuidado, mas também de novos mecanismos geradores de sofrimento. A introdução de mudanças tecnológicas e gerenciais na empresa investigada - aliada ao seu projeto de privatização - agravava o sofrimento:

"A transformação da empresa acelerou o
sofrimento, poucos estão conseguindo
acompanhar, está no nível de enxugar tudo.
Aquela pessoa que está numa posição
confortável fica ameaçada e às vezes adoece.
Porque ali já tem gente demais do padrão
dele. Então, ele começa a sentir que pode ser
a bola da vez" (XD, gestor do setor
administrativo).

Tais mudanças desorientavam e intensificavam o sofrimento, uma vez que, mergulhados num imaginário de prejuízos, os trabalhadores não sabiam que caminhos seguir:

\begin{abstract}
"Já não sabia mais o que fazer. Eu pedi transferência de setor para sair daquele ambiente que cobrava além do que eu podia fazer, estava dando o máximo. Mudaram tanto as coisas que ficaram além do que eu poderia oferecer. Cheguei a pensar em demissão, mas o que sei fazer só existe aqui. Eu passava noites sem dormir, então procurei um médico. Fiquei afastado três dias, estou usando calmante para os nervos" (HD, trabalhador do setor operacional).
\end{abstract}

Se tudo poderia mudar a qualquer hora, o processo de adoecimento oferecia tempo e permanência ilusórios que, mesmo assim, não os relaxava diante do estado de alerta em que se encontravam.

$\mathrm{Na}$ tentativa de se livrar do sofrimento, como se ele fosse o problema, o sujeito reorganizava a sua atividade e reconstruía a sua trajetória de acordo com aquilo que imaginava ser melhor para si, deixando de lado a dimensão coletiva. Mesmo nessas circunstâncias, nada restava senão agir. No entanto, inúmeras estratégias isoladas colocavam seus autores em novas situações de risco, dada a ausência de uma instância ordenadora para as práticas grupais. Como um combatente emaranhado na rede da vontade individual, lutava, sofria e entrincheirava-se. Experimentava em si a angústia do isolamento, que, para Nietzsche $(1871 / 1978$, p. 10) era "um estado de individuação como fonte e o primeiro fundamento de todo sofrimento, como algo repudiável em si mesmo".
No entanto, esse sofrimento parecia uma dimensão proibida de se manifestar. Ao afirmarmos a existência da transformação do sofrimento em adoecimento, na gestão do trabalho, inquirimos: como ele acontece? Sempre que o homem abre o olho e o ouvido, expõe seu coração, trabalha e constrói o pensamento, encontra-se já na busca daquilo que ainda não foi revelado. A partir daí ele mistura o recôndito em si com a existência a cultivar (Heidegger, 1954). Então nos perguntamos pelos dispositivos dessa transformação. Esse era o nosso destino e, para tal, seria necessário arriscar-nos pelos caminhos do revelar, ou seja, poderíamos nos perder no nãorevelado e, conseqüentemente, interpretá-lo falsamente. No entanto, tínhamos em mente que o ato de pesquisar, como desejo de saber, comportava destino e risco, mas precisávamos compreender como os dispositivos se formam, articulam-se e se comportam. Para tanto, interpretamos os depoimentos baseados nos pressupostos heideggeriano de que uma revelação sucede a uma permanência e se manifesta, em seu aspecto fenomênico, como uma permanência. Por isso relacionamos o processo de transformação do sofrimento em adoecimento não apenas com a produção e reprodução de discursos - que vão do nascimento da clínica, no século XIX, à psicodinâmica dejouriana, segundo Brant e Minayo-Gómez, (2004) -, mas também com um conjunto de dispositivos (Einrichtungen) institucionais, instrumentos utilizados para atingir um fim, como tentaremos evidenciar em seguida.

\section{O esgarçamento da figura da autoridade}

A autoridade, em sua função política de oferecer aconselhamento para se viver mais e melhor em comunidade, acrescenta e desenvolve os fundamentos estabelecidos pelos ancestrais. A continuidade "desse aumentar" só pode ocorrer através da tradição, da transmissão da norma inaugural, passada de geração a geração. Partindo desses princípios, Arendt (2001) pergunta pelo destino da autoridade, uma vez que ela desapareceu do mundo moderno, e relaciona essa perda com as rápidas transformações nos campos da cultura e da ciência ocorridas a partir do século XVI. Os processos de reestruturação organizacional da era pós-industrial, com suas exigências de mudanças velozes, vêm reforçando essa perda e gerando crises constantes e cada vez mais profundas na gestão do trabalho.

$\mathrm{Na}$ empresa estudada, o curto prazo para cumprir as metas do processo reestruturativo suscitava nos gestores mais novos o ímpeto de resolver competentemente os problemas, em quaisquer 
circunstâncias, acabando por fortalecer, em alguns, o mito de uma reestruturação plenamente possível. O depoimento do gestor TR aponta nessa direção:

"Você tem que ser super-homem, tem de ser tudo. Tenho que me extrapolar nas minhas ações, dedicar full time, porque o sistema não é tão estável, enferruja; a máquina adoece. Tenho que lutar contra o tempo, o mundo."

Como no Fausto, de Goethe, o entrevistado parecia não reconhecer as impossibilidades da vida, em suas ações não havia lugar para a dúvida, para a percepção dos limites humanos: "Você tem que suportar tudo, engolir tudo, calango, lagartixa, jacarés". Parecia capaz de ir do céu, através do mundo, até o inferno (Goethe, 1970). Revela, ainda: "Você não pode deixar a empresa em má situação, tem muita gente despreparada, são até esforçados. Aí, você tem que ser muito bom, evitar e corrigir as falhas deles. Não é só leitura, é ação, questão de vida ou morte". Como resultado do desaparecimento da figura da autoridade, esse gestor surgia como um sujeito investido de um poder institucionalmente delegado, e o assumia narcisicamente. A existência dessa crença onipotente em si mesmo, em alguns gestores, não pertence somente ao sujeito, não é exclusiva de uma subjetividade obsessiva e narcísica. Numa cultura do pleno poder pessoal e da competência, a impossibilidade não tinha lugar, pois, como observa FR, profissional da saúde, o "discurso da organização é que o possível eu faço agora, o impossível vai demorar um pouco. Isto ficou como uma norma, ou seja, você pode fazer muito mais do que você sabe". Para esse profissional, tal visão constituía a tônica da maioria dos gestores formados pela escola gerencial da própria empresa.

O gestor, no exercício do cargo, ao ser substituído por um recém-formado, dificultava a transmissão de práticas gerenciais autênticas e incontestes, compartilhadas apenas com certos grupos. Esses gestores detinham uma experiência de trabalho que a escola de administradores não tinha como oferecer, o que provocava bloqueios na articulação de pólos de identificação e dificuldades de assegurar a ordem e a coesão grupal:

"Tiram você da chefia e você fica sabendo assim, num estalo de dedos. É um choque, né? É como se tivesse levado um pontapé no traseiro... Aí, interrompe os planos do trabalho. O novato começa a fazer tudo diferente, nem sabe o que estava sendo desenvolvido... Aí, ninguém entende mais nada, nem o que você fazia antes... Já que é assim, também não explico como era." (ML, gestor do setor operacional).

A interrupção da transmissão do saber-fazer construído no cotidiano e estrategicamente passado pela tradição oral "apenas àqueles que faziam parte dos nossos", durante a reestruturação, era um dispositivo de resistência e, apenas aparentemente, estava relacionado com desmotivação, como alguns profissionais a interpretavam.

Os gestores recém-empossados, verdadeiros estrangeiros no setor, administravam mediante um poder forte, mas com uma autoridade desgastada:

\begin{abstract}
"Antigamente, os chefes eram mais respeitados, eram como os pais, um exemplo para ser seguido. Agora, cada semana você tem um supervisor diferente, que só sabe dar gritos e mandar para o médico, é uma confusão. São ordens de tanta gente, que você fica sem saber quem é o chefe mesmo, você fica perdido..." (JF, trabalhador do setor administrativo).
\end{abstract}

A falta de recursos gerenciais básicos demonstrava não só o esgarçamento da autoridade, mas a utilização de um canal institucional - o setor de saúde - como estratégia para a solução de problemas administrativos e gerenciais:

\begin{abstract}
"chega um momento que você pede socorro ou você simplesmente abandona. Quando a ajuda não vem, é você sozinho mesmo. Quando não dava conta de um empregado, eu mandava para o setor de saúde, era a solução, vi outros chefes fazendo isso. Os médicos sabem se é enrolação ou doença, através dos exames que fazem. Como era novo no cargo e era a primeira vez que eu chefiava, eu não era respeitado" (TG, gestor do setor administrativo).
\end{abstract}

Essa estratégia de recorrer ao setor de saúde reflete a própria falência da autoridade no desempenho da função gerencial.

\section{A construção da identidade de doente}

Para Herzlicch e Pierret (1987), é no século XIX que a figura do doente cristalizou-se existencial e socialmente, assumindo a sua forma moderna e emergindo não apenas como um indivíduo, mas também como fenômeno social. Desde então, o doente passou a ser definido a partir do diagnóstico do médico. Há uma diferença entre discurso médico e discurso do médico. Essa se faz à medida que o 
primeiro se refere ao cuidado dispensado por um sujeito qualquer a outro, enquanto o segundo assinala a presença de um profissional cuja formação e titulação ocorreu no âmbito de uma escola de medicina. Ser doente ou não é fruto de uma interpretação, como muito apropriadamente nos lembra Nunes (1987), pois é realizada pela linguagem que possibilita não só objetivar a experiência cotidiana, estruturada espacial e temporalmente, mas também determinar a ordem através da qual os objetos ganham sentido e na qual a vida cotidiana ganha um significado. Portanto, ser nomeado, dizer-se ou apresentar-se como doente, constituem identificações atribuídas e mantidas socialmente, situadas nos domínios culturais e sociológicos, e não apenas no âmbito da clínica.

$\mathrm{Na}$ atualidade, existe uma tendência a delinear e classificar a queixa inicial como uma síndrome:

\begin{abstract}
"Estou com medo, a empresa está privatizando. Eu tenho jogado no corpo tudo, dor no ombro, nas costas, formigamento nos braços (...). Aí tenho licença de três dias, mais exames e mais remédios. Estou sempre no médico. Cada um dá um diagnóstico; de síndrome do pânico até de hipocondria”. (VC, gerente administrativa).
\end{abstract}

No discurso do médico, além de o sofrimento ter um registro em órgãos, o sujeito precisava assumir-se como doente para ser atendido no âmbito da clínica. A forma de intervenção também foi modificada. Já não se faz totalmente na direção da cura, no sentido biomédico, mas como regulação do sofrimento, incorporando o paradigma das neurociências. "Estou sempre no médico". Essa era a forma que a paciente encontrava para obter uma compreensão, mas pouco entendia a resposta médica. A dificuldade não se fazia pela ausência de um vocabulário para comunicar seus sintomas ao médico, mas por não ver sua queixa reconhecida. Já a dificuldade da ausculta profissional estava relacionada ao discurso biomédico, que só reconhecia a dor, o inchaço e o rubor. Com a experiência, o paciente aprendia: "É melhor que eu não fale: isto cansa o médico" (Clavreul, 1983 p. 158). Portanto, "jogar tudo no corpo" constituía também uma estratégia para ser compreendida em seu sofrimento, mesmo correndo o risco de ser rotulada como hipocondríaca, o que a inseria de vez no modelo das neurociências.

O médico do trabalho sabia, de antemão, que se deparava com o exercício de uma rotina gerencial de atender trabalhadores encaminhados para a consulta pelos gestores. Poderia se deparar com pessoas que tinham problemas de saúde ou que estavam ali porque criavam dificuldades na seção: "quando o empregado enche o saco do gestor, ele manda pra gente" (AM, profissional da saúde). Nesse caso, fica evidente que "existe a transferência de uma responsabilidade do gerente, que é de gestão, para a parte médica" (CO, profissional da saúde). Os procedimentos baseados no sentimento de pena por parte do profissional da saúde, na relação com o trabalhador, durante a consulta, constituíam alguns dos elementos formadores da identidade de doente na empresa. Desqualificado como sujeito capaz de reação, e vítima do gestor, era visto pelo médico como alguém que precisava da sua compaixão, jamais como portador de um sofrimento:

“A gente faz avaliação clínica. Então, ele (chefe) devolve, não o aceita, alegando que ele não está respondendo à expectativa do trabalho. Às vezes, tinha que afastar o funcionário porque ele ficava muito melindrado com a possibilidade de demissão, eu mesmo tinha pena do funcionário. Porque é a única forma de proteger o trabalhador" (CO, 42 anos, profissional da saúde).

Nesses casos, a visibilidade do sofrimento atingia o médico, despertando sentimento de dó. Esse profissional, embora competente em sua formação biomédica, carecia de subsídios capazes de permitir a leitura do sofrimento presente naquela situação e a busca, com o trabalhador, de alternativas ao afastamento.

Outras vezes, as expressões de sofrimento, enquanto reações de enfrentamento, eram abortadas pela imposição da chefia imediata, no momento do encaminhamento ao médico.

"Eu insistia em ficar trabalhando, mesmo mancando; doía, trabalhava numa favela, ia dando o meu jeito, daqui, dali, a trancos e barrancos. Mas aí não teve jeito, o supervisor me obrigou a ir para o médico. Tinha medo de ser afastado e isso sujar minha ficha funcional e a avaliação de desempenho, eu disse isso pro doutor. Mas ele falou que isso é normal, todo mundo que trabalha naquele lugar tem esse problema. Que só dependia de mim. Mandou tirar raios-X dos joelhos, tomar Cataflan e voltar depois" (LG, trabalhador do setor operacional).

Diante das dificuldades de readaptar esse trabalhador a outra área, compatível com sua capacidade laborativa residual, o médico não tinha alternativa senão afastá-lo, deixando-o numa situação de desamparo; claramente percebida pelo paciente, como se pode verificar através da frase: “...que só dependia de mim”. 
Em outras ocasiões, os diagnósticos explicitavam a utilização do discurso da neuropsiquiatrização como base, que redundava na culpabilização do trabalhador:

\begin{abstract}
"as pessoas se afastam por LER, problemas de vários tipos, problemas psicológicos. Então, a pessoa não está bem com ela. Tem uma funcionária afastada por LER, inventou mil coisas, porque ela não consegue assimilar a cobrança de trabalhar aqui dentro. Mas ela estava até bem, ela foi para outra área e desestruturou a cabeça dela; acho que a pessoa está no limite, qualquer mudança mínima faz com que ela adoeça" (BN, profissional da saúde).
\end{abstract}

Responsabilizando o trabalhador pelo que the sucedia e enquadrando-o na categoria de doente, em grande número de casos, o sofrimento era interpretado como psicossomatização. Essa prática no trato das questões das lesões por esforços repetitivos (LER), em sintonia com uma rede discursiva psiquiatrizante, socializada através da mídia e de publicações especializadas, contribui para a formação de uma visão neurótica do trabalhador (Verthein \& MinayoGómez, 2001).

$\mathrm{Na}$ configuração da identidade de doente, as intervenções nos casos de dependência química são exemplares, inclusive dada a sua elevada incidência e uma legislação ambígua que leva a demissões por justa causa.

"O doutor falou que é doença, que eu era um doente. Bebo mesmo! Mas, quando quero, paro de beber. Não sou doente, sou é tímido. $\mathrm{O}$ doutor falou em me internar e em depressão; pedi para não colocar que era por causa de álcool. Respondeu que se não especificar a doença, o hospital e o INSS não aceitam. Tinha que ter um número, até hoje, não esqueci, um tal de F10." (GC, trabalhador do setor operacional).

Partindo do princípio de que a vida, em seu cotidiano, é uma realidade interpretada, a afirmação "o doutor falou que é doença, que eu era um doente" é inapropriada. A interpretação do paciente - "eu não sou doente, sou tímido" -, fruto da experiência da vida, parece não fazer sentido para seu interlocutor. A sugestão de internação e a atribuição do F10 - da Classificação Internacional de Doenças (CID-10) - indicam que a identidade de doente estava se configurando durante a consulta. A preponderância da interpretação do clínico, em detrimento da fala do paciente, leva-nos a pensar na força de que o discurso médico ainda goza na sociedade atual, dificultando a visibilidade da milenar articulação entre sujeito e sofrimento (Foucault, 1998).

\section{A sustentação da enfermidade e o mascaramento do sofrimento}

Inicialmente, a visibilidade ou o tamponamento do sofrimento pareciam relacionados ao cargo. Posteriormente, notamos a presença de outras variáveis que interferiam em seu destino: a trajetória na empresa, as condições de trabalho, as estratégias utilizadas para ocupação do cargo, as expectativas quanto à carreira e o significado atribuído pelo trabalhador e sua família à função eram alguns dos elementos determinantes desse tamponamento. Por fim, constatamos que os benefícios previdenciários também favoreciam a construção de estratégias para provar que o sofrimento implicava, necessariamente, a presença de enfermidade, principalmente entre trabalhadores mais antigos do setor operacional e com baixo grau de escolaridade. Com as perdas salariais, os benefícios proporcionavam um impacto positivo no orçamento doméstico.

$\mathrm{O}$ trabalho rotineiro de $\mathrm{PK}$ (trabalhador operacional) o expunha ao tédio e a riscos insidiosos que, em longo prazo, comprometeram, gradativamente, sua saúde. Segundo seu depoimento, "estar afastado aumenta o pagamento em quase $100 \%$. Ficar doente é ótimo, do ponto de vista financeiro. Tem salário mais complementação do pecúlio e não tem os descontos. Minha esposa insistia para que eu ficasse encostado até aposentar por invalidez". A ilusão de que a licença médica redundava em "salário maior" era vivida, em família, como recompensa pela dedicação, e deslocava o foco da preocupação com a saúde para a monetarização do afastamento. Observamos que algumas esposas colaboravam com o tratamento, contribuindo para a estabilidade do quadro clínico até às vésperas da perícia do INSS, quando compactuava com o marido na utilização de práticas que favoreciam a emergência de uma crise ou que evidenciavam a permanência da morbidade.

\footnotetext{
"Quando vai chegando o dia da perícia fico muito nervoso; se voltar a trabalhar, sei que depois serei mandado embora, mesmo sendo hipertenso e alcoolista. Aí, minha mulher começa a fazer comida mais salgada, não corto cabelo nem barba e bebo bons goles. De cara, já vou entregando o relatório do psiquiatra para o perito e a minha mulher dispara a falar mal de mim" (PK, trabalhador operacional).
}

A estratégia do adoecimento, como último recurso, e a sua utilização metódica tornavam-se um dispositivo que dificultava, radicalmente, o enfretamento do sofrimento e sua relação com as condições de trabalho, que envolvia tarefas penosas, de operação simples e repetitiva. Constatamos também que, nas tentativas de reinserção no 
trabalho, esses trabalhadores reivindicavam não mudar de posto, parecendo desejar os agravos à saúde e, com eles, o sonho da aposentadoria precoce, na esperança de reconstruir sua vida em outro lugar, sustentando a imagem de um homem que era "operário-padrão", mas adoeceu.

Por outro lado, em alguns depoimentos, constatamos fortes tentativas de manutenção da imagem de saudável e de bem-sucedido. Em estudos realizados por Brant e Dias (2004) nessa empresa, verificamos que as principais manifestações do sofrimento eram, entre os gestores, angústia (73,2\%); tristeza (43,7\%); insatisfação $(39,0 \%)$. No esforço de compreender as estratégias utilizadas para o mascaramento do sofrimento, deparamo-nos com o relato do gestor administrativo WA:

"ter depressão e estresse é natural no líder, mas, hoje, temos bons medicamentos, clínicas de repouso e de autodesenvolvimento especializadas para executivos, você sai rejuvenescido, pronto para o seu posto. Se todos fizessem isso, teríamos as pessoas certas nos lugares certos. Só vou ao médico fora do horário da empresa e não procuro conveniados".

A construção e a sustentação da imagem de sucesso do profissional constituíam um dispositivo estético para provar a possibilidade de soluções puras e assépticas numa reestruturação. Colocar em evidência gestores saudáveis e satisfeitos tinha por objetivo apresentar um terreno agradável e um clima organizacional tranqüilo e livre de conflitos. No entanto, todo culto à imagem evidencia a fragilidade da ordem, que, uma vez percebida como tal, exigia novas ordens, na busca do sonho da pureza; assim, parecia estar esquecido que todo programa de higiene produz grandes sujeiras (Bauman, 1998).

$\mathrm{O}$ processo de reestruturação parecia ter encarnado a cultura da sociedade do bem-estar de corpos harmonizados, na qual manifestar sofrimento tornou-se motivo de vergonha e fracasso pessoal. Parecia seguir "um princípio intangível: todo indivíduo tem o direito e, portanto, o dever de não mais manifestar seu sofrimento" (Roudinesco, 2000, p. 16).

\footnotetext{
"Tive mudança na minha saúde, um impacto. Procurei o clínico da empresa, mas não coloquei a situação, disse que era um malestar. Perguntaram sobre o trabalho, disse que estava tudo tranqüilo. Mas não relatei o que aconteceu. Procurei um médico particular, tive uma crise de hipertensão, depressão e estresse, estou usando vários medicamentos. A chefia não percebeu nada.
}

Sofri em silêncio" (NM, gestor do setor administrativo).

Qualquer manifestação de sofrimento implicava na busca de ajuda fora da empresa, acreditando na existência de medicamentos para alívio imediato.

Apesar das estratégias empreendidas, algumas situações de morbidade, no meio gerencial, adquiriam intensa visibilidade: "Eu engordei bastante, os sintomas de hipertensão só foram agravando, muita dor de cabeça. Nas crises, levavam-me do trabalho para o hospital, aí foi um afastamento atrás do outro ... coisas da vida." (ML, gestor do setor de administração). Diferentemente do sofrimento, doenças reconhecidas socialmente como naturais não comprometiam a imagem. Pelo contrário, eram representadas como evidências de dedicação ao trabalho ou próprias da idade. Sendo vítima de "coisas da vida", nenhuma relação era feita entre condições de produção e adoecimento, o que fazia desse trabalhador um modelo. Tamponar o sofrimento visto como sinal de fraqueza e, estrategicamente, realçar a doença como norma da vida, mas não do trabalho, foi a maneira que a organização encontrou para manter a imagem do ideal de competência na reestruturação.

A falta de ação afetava não somente a sobrevivência do sujeito, mas a própria organização coletiva dos trabalhadores, em que inexistiam perguntas do tipo: "Quem necessita de mim, nesse momento?" Em sua dimensão social, a desafiante responsabilidade para com o outro parecia impossível, no processo de reestruturação da empresa, diante da alta competitividade. "Como alguém conta comigo, eu sou responsável por minha ação perante outro" (Ricoeur, 1992, p. 166). Se, para esse autor, uma ação só é possível desde que haja uma testemunha observando o que dizemos e fazemos, ou seja, alguém que conta conosco, nas ações para com o próximo, a palidez da figura da autoridade constituirá elemento central do processo de transformação do sofrimento em adoecimento.

\section{CONSIDERAÇÕES FINAIS}

Concluímos que as manifestações do sofrimento constituem um verdadeiro tabu. Sua presença foge à rotina da gestão empresarial e de seus serviços de atenção à saúde. $\mathrm{O}$ trabalhador, desamparado e sem elementos lingüísticos necessários para formular sua real demanda, é encaminhado ao setor médico, que detém um discurso aparentemente capaz de nomear suas manifestações e de proporcionar soluções imediatas. Logo, o diagnóstico, medicação, licença médica e hospitalização, constituíram os primeiros dispositivos capazes de transformar a 
manifestação do sofrimento em adoecimento. Tais mecanismos, aparentemente, apaziguam por meio de explicações sobre o vivenciado, aliviam os sintomas, trazem a esperança da cura, oferecem uma resposta passageira ou recolhimento, repouso e cuidados intensivos. Remetem, ainda, a um aparato jurídicoinstitucional capaz de garantir amparo e benefícios até para a vida toda. Particularmente, nesse ínterim - entre a expressão do sofrimento nas relações de trabalho e a instituição previdenciária - encontra-se a construção da identidade de doente, a sustentação da enfermidade e o mascaramento do sofrimento como outros dispositivos da transformação em adoecimento. De forma semelhante, as neurociências, enquanto campo teórico, de intervenção e de extraordinária produção farmacêutica, não visaria tanto à cura, mas principalmente à regulação do sofrimento, constituindo-se também em significativo dispositivo na produção do adoecimento.

No entanto, esse itinerário só é possível mediante certa disposição do trabalhador para postar-se nesse lugar, iniciado com o adoecimento e concluído, em muitos casos, com a aposentadoria por invalidez. Portanto, esses dispositivos constituíam-se desde encaminhamento para a consulta e chegava até ao laudo conclusivo de uma aposentadoria por invalidez, passando pelo diagnóstico de uma doença. Essa disposição, facilmente confundível com ausência de reação, traz em seu cerne complexas estratégias de sobrevivência, não por parte não apenas dos trabalhadores, como inicialmente se poderia pensar, mas de todos os envolvidos na gestão do trabalho, notadamente, gestores e profissionais da saúde. Os primeiros, com o exercício da autoridade desgastada para gerenciar recursos humanos, sobretudo os mais conflituosos, recorrem ao setor saúde para obter ajuda. Os outros, formados pelos cânones da biologia e da fisiologia - com um olhar inteiramente voltado para o corpo e seu funcionamento -, pouco tinham a oferecer além dos procedimentos anteriormente apontados, embora o esforço de alguns em lidar com o sofrimento seja perceptível. Assim, na empresa estudada, trabalhadores, gestores e profissionais da saúde, a partir de diferentes lugares e dispositivos institucionais, buscavam sua sobrevivência durante o processo de reestruturação organizacional, pois tinham em comum um vínculo empregatício a preservar.

\section{REFERÊNCIAS}

Arendt, H. (2001). Entre o passado e o futuro. São Paulo: Perspectiva.
Bauman, Z. (1998). O mal-estar da pós-modernidade. Rio de Janeiro: Jorge Zahar.

Birman, J. (2006). Arquivos do mal-estar e da resistência. Rio de Janeiro: Civilização Brasileira.

Brant, L. \& Dias, E. (2004). Trabalho e sofrimento em gestores de uma empresa pública em reestruturação. Cadernos de Saúde Pública, 20(4), 942-949.

Brant, L. \& Minayo-Gómez, C. (2004). Do nascimento da clínica à psicodinâmica do trabalho: a transformação do sofrimento em adoecimento. Rio de Janeiro: Ciência e Saúde Coletiva, 9(1), 213-223.

Canguilhem, G. (2000). O normal e o patológico. Rio de Janeiro: Forense Universitária.

Clavreul, J. (1983). A ordem médica. São Paulo: Brasiliense.

Deleuze, G. (1992). Conversações. Rio de Janeiro: 34.

Foucault, M. (1979). Microfísica do poder. Rio de Janeiro: Graal.

Foucault, M. (1998). O nascimento da clínica. Rio de Janeiro: Forense.

Freud, S. (1997). O mal-estar na civilização (J. Salomão, Trad.). Edição Standard Brasileira das Obras Psicológicas Completas. Rio de Janeiro: Imago. (Original publicado em 1930).

Goethe, J. (1970). Fausto. Rio de Janeiro: Jackson. (Original publicado em 1832).

Heidegger, M. (1954). Vorträge und aufsätze, pfullingen güter neske. Verlag: Frankfurt.

Herzlicch, C. \& Perret, J. (1987). Illness and self in society. Baltimore: Johns Hopkins University.

Levi-Strauss, C. (1974). Antropologia estrutural. Rio de Janeiro: Tempo Brasileiro.

Machado, R. (1999). Nietzsche e a verdade. Rio de Janeiro: Paz e Terra.

Minayo, M. \& Deslandes, S. (2002). Caminhos do pensamento: epistemologia e método. Rio de Janeiro: Fiocruz.

Nietzsche, F. (1978). O nascimento da tragédia no espírito da música. Em F. Nietzsche (Org.), Os pensadores (pp. 7-22). São Paulo: Abril Cultural. (Original publicado em 1871).

Nunes, C. (1987). Reconstrução da memória. Cadernos de Pesquisa, 61, 72-80.

Ricoeur, P. (1992). Oneself as another. Chicago: University.

Roudinesco, E. (2000). Por que a psicanálise? Rio de Janeiro: Jorge Zahar.

Sennet, R. (2000). A corrosão do caráter. Rio de Janeiro: Record.

Verthein, M. \& Minayo-Gómez C. (2001). As armadilhas: bases discursivas da neuropsiquiatrização das LER. Ciência \& Saúde Coletiva, 6(2), 457-470.

Endereço para correspondência: Luiz Carlos Brant. Cesteh. Rua Leopoldo Bulhões, 1480, Manguinhos, Cep 21041-210 Rio de Janeiro.E-mail: interfaz@interfaz.com.br 